\title{
Perspective
}

PERSPECTIVE Actualité en histoire de l'art

4 | 2007

Genre et histoire de l'art

\section{Représenter les sexes. Images et genres dans l'Antiquité grecque}

Depicting the sexes. Images and gender in Greek Antiquity

Geschlechterdarstellungen. Bild und Geschlecht in der griechischen Antike

Rappresentare la sessualità. Immagini e generi nell'Antichità greca

Representar los sexos. Imágenes y généros en la época clásica griega

\section{Violaine Sebillotte Cuchet}

\section{(Q) OpenEdition}

Journals

Édition électronique

URL : http://journals.openedition.org/perspective/3570

DOI : $10.4000 /$ perspective. 3570

ISSN : 2269-7721

Éditeur

Institut national d'histoire de l'art

Édition imprimée

Date de publication : 31 décembre 2007

Pagination : 626-648

ISSN : $1777-7852$

Référence électronique

Violaine Sebillotte Cuchet, "Représenter les sexes. Images et genres dans l'Antiquité grecque ", Perspective [En ligne], 4 | 2007, mis en ligne le 09 octobre 2013, consulté le 01 octobre 2020. URL: http://journals.openedition.org/perspective/3570; DOI : https://doi.org/10.4000/perspective.3570 


\title{
Représenter les sexes. Images et genres dans l'Antiquité grecque
}

\author{
Depicting the sexes. Images and gender in Greek Antiquity \\ Geschlechterdarstellungen. Bild und Geschlecht in der griechischen Antike \\ Rappresentare la sessualità. Immagini e generi nell'Antichità greca \\ Representar los sexos. Imágenes y généros en la época clásica griega
}

Violaine Sebillotte Cuchet

1 Les questionnements sur les images interrogées dans une perspective de genre mettent en cause des disciplines différentes (histoire, archéologie, histoire de l'art) dont les problématiques se sont développées à partir de méthodologies spécifiques. Surtout, le genre, comme notion, a des significations très variées et rarement explicitées (Fougeyrollas et al., 2003). Deux synthèses récemment publiées (FERRARI, 2002 ; LEWIS, 2002), les plus importantes publications à ce jour à la fois pour la portée de leurs interprétations et la divergence de leur méthode, la perspective de Françoise FrontisiDucroux (FronTISI-Ducroux, 2004), une abondante et récente historiographie témoignent du dynamisme de ce champ de recherche et amènent à revenir sur ces questionnements, leurs méthodes et leurs enjeux.

2 Pour aller au plus simple, le genre se définit comme l'ensemble des assignations socialement construites à partir de l'identité sexuelle (GoDELIER, 2005; SEBILLOTTE CUCHET, 2007). En faisant porter l'accent sur la non-adéquation du sexe et du genre, les gender studies travaillent donc moins sur les sexes eux-mêmes que sur leur interprétation. S'il s'agit ainsi moins souvent d'étudier les femmes que le féminin, c'està-dire l'ensemble des significations associées aux femmes, il en est de même avec les hommes: alors que ceux-ci sont objets d'histoire depuis bien longtemps, l'étude du masculin est directement liée à l'histoire du genre. Dans ces conditions, les rapports entre les hommes et les masculinités, entre les femmes et les féminités, constituent l'aspect le plus complexe qu'aient à traiter ces études. Elles s'inscrivent dans la problématique plus générale de la représentation. 
3 Après une période d'exploitation documentaire sur la (mauvaise) condition féminine surtout à partir des discours des orateurs attiques, la lecture des textes d'Homère à Aristote, notamment avec l'intérêt porté aux tragédies et aux comédies attiques, a favorisé l'étude des représentations. Les historiens ont dès lors beaucoup décrit le ou les féminins au risque de perdre de vue ses références concrètes, les femmes.

En se tournant vers les images, l'approche documentaire reprend aujourd'hui de la vigueur sans pour autant que soit délaissée la piste des représentations. L'importance des personnages féminins dans le répertoire iconographique, mise en relation avec les nombreuses attestations fournies par l'archéologie (et notamment l'épigraphie), atteste que nombre de femmes ont pu être valorisées ou accéder à des situations de prestige, ce qui vient nuancer le discours historien traditionnel sur la cité grecque constituée comme un club d'hommes. Parallèlement, la prise en compte de la spécificité du langage iconographique enrichit la description des systèmes de genre. Une syntaxe et un lexique adaptés à la figuration (peinture sur vase et, dans une moindre mesure, reliefs) construisent un imaginaire où les différences de sexe tiennent souvent une part importante: des ensembles d'objets, des vêtements spécifiques, des positions et des relations entre personnages paraissent liés plutôt à l'un ou l'autre sexe. La troisième direction de recherche, plus théorique, s'attache aux cas où les marqueurs du féminin et du masculin sont associés à des personnages de sexe opposé. Ces apparentes transgressions illustrent tout simplement le caractère construit du genre: il est signifiant, indépendamment du sexe; il n'a pas à être en adéquation parfaite avec lui. L'interrogation est alors portée sur la signification de ces étrangetés: que nous apprennent-elles sur les hommes et les femmes de la Grèce archaïque et classique, sur leurs manières de penser la différence des sexes, sur les éléments réellement en jeu dans le rapport hiérarchique entre les individus?

\section{La question documentaire : l'archéologie des représentations}

5 Le discours des historiens sur l'organisation des sexes est en grande partie issu d'une lecture des sources littéraires. Les affaires de la cité sont des affaires d'hommes qui concernent essentiellement la vie politique, la guerre et la diplomatie, la philosophie et la médecine. Les femmes représentent une moitié problématique dont personne ne nie la fondamentale importance. Elles sont des agents essentiels de la reproduction de la cité et sont pourtant tenues dans une subordination permanente. Différentes hypothèses, aujourd'hui plus souvent de nature psychologique (les hommes seraient fascinés et auraient peur des femmes) que de nature biologique (infériorité naturelle de la femme), tentent d'expliquer les raisons de cette subordination, partie intégrante de l'idéologie civique (LORAUX, 1981a, 1981b, 1985, 1989, 1990 et 1999).

6 Bien évidemment, les données archéologiques ne peuvent renseigner sur les motifs de l'exclusion des femmes; en revanche, elles peuvent nuancer nos conclusions en faisant émerger des domaines d'activités qui, s'ils n'intéressaient pas les auteurs antiques, intéressaient les artistes. Les données iconographiques, souvent croisées avec d'autres éléments archéologiques, sont alors utilisées comme des éléments de réel couvrant des absences documentaires. 


\section{Éléments de réel et scènes de fantaisie}

7 Des éléments de réalisme sont ainsi, et souvent à juste titre, recherchés dans les images, notamment ce qui concerne les décors, les objets représentés, les vêtements portés, voire les gestes des personnages. Un article récent propose d'ailleurs de nouvelles directions de recherche sur la question du genre du vêtement tout en soulignant à quel point la frontière est floue entre le codage réalisé par les peintres et l'illustration documentaire qu'ils trahissent : le peintre est censé utiliser des realia mais les détourne pour une véritable mise en scène; le travail de l'interprète réside dès lors dans l'appréciation de la nuance (GHERCHANOC, HUET, 2007). Ainsi, que penser des métiers à tisser représentés sur les vases, bien plus petits que ceux utilisés en réalité pour la confection des tissus? La raison semble en être d'ordre pratique et esthétique: la surface du vase n'est pas assez grande pour respecter les proportions et c'est bien entendu l'équilibre de la composition qui prime. Le métier à tisser parfois préféré des peintres, tenu à la main et horizontal, ressemble alors à une lyre, belle occasion de souligner la métaphore poétique du tissage comme chant (LewIS, 2002, p. 65, note 15). De même, alors que les grands métiers verticaux effectivement utilisés produisaient de larges pièces textiles, les femmes travailleuses dépeintes sur les vases s'affairent autour de petites pièces de tissus. On en déduit que la question de la production intéresse moins l'artiste que la valeur symbolique du travail de la laine.

Ces remarques de méthode sont bien connues (LISSARRAGUE, 1991; FronTISI-DucrouX, LISSARRAGUE, 2004). François Lissarrague a rappelé récemment à quel point les représentations sur vases sont travaillées par la phantasia [imagination] notamment lorsqu'elles tentent de représenter l'invisible, tel l'effroi produit par des figures comme les Érinyes (LISSARRAGUe, 2006). Comment démêler alors ce qui relève du quotidien des artistes, de celui des utilisateurs des vases aux $\mathrm{vI}^{\mathrm{e}}$ et $\mathrm{v}^{\mathrm{e}}$ siècles, et ce qui relève de l'imaginaire, celui d'un monde peuplé de héros, de dieux et de monstres? Est-il productif de chercher à repérer des éléments de réel et ne risque-t-on pas toujours de se faire piéger par le détournement effectué par les peintres? Comment savoir, par exemple, si la femme au parasol poursuivi par un satyre couronné sur le skyphos de Berlin est bien l'épouse de l'archonte-roi d'Athènes représentée lors du rituel du hiéros gamos [mariage sacré] des Anthestéries, le mariage avec Dionysos? Ne s'agirait-il pas plutôt d'une scène totalement imaginaire relevant d'un fantasme masculin: se transformer en satyre pour s'attaquer à une jolie dame (LewIs, 2002, p. 53) ? De la même façon et sans pouvoir davantage trancher sur le sens à donner aux images, les étranges scènes de copulation qui se déroulent sur une coupe rhodienne renvoient-elles à des rituels qui nous sont inconnus ou bien développent-elles des connotations apotropaïques, telles celles que Sian Lewis relève dans l'imagerie étrusque? Sur cette dernière question, nous ne suivrons cependant pas ses affirmations concernant l'influence d'un imaginaire étrusque sur les artistes grecs (LEWIS, 2002, p. 116-120 et spécialement p. 117) que rien dans son livre ne permet d'étayer de façon décisive.

9 La fameuse hydrie de Milan est souvent utilisée comme exemple, si rare, du travail artisanal des femmes: ici on voit une femme ouvrière dans un atelier de bronzier occupé par des hommes (Lewis, 2002, p. 90). Cette femme à l'ouvrage qui décore les anses du cratère est représentée sur une estrade, à l'écart des autres ouvriers. La présence d'Athéna et d'une Nikè qui couronnent les seuls personnages masculins de la scène laissent sceptique sur une interprétation réaliste de l'ensemble. Est-il nécessaire 
d'associer au vase l'inscription mentionnant, au $\mathrm{IV}^{\mathrm{e}}$ siècle, Dionysios le fabricant de casques et sa femme Artémeis, décoratrice (Inscriptiones Graecae, III. III. 69), pour interpréter la scène de l'hydrie comme la reproduction d'un atelier composé d'un patron, de ses ouvriers et de son épouse ? S. Lewis, prenant le risque de l'identification, voit ainsi dans le couronnement divin la note humoristique d'une femme peintre se projetant elle-même dans la scène de l'atelier dirigée par son époux (LEWIS, 2002, p. 91). D'un autre côté, considérer le personnage féminin comme un modèle divin, à l'image d'une Athéna, est une manière un peu cavalière de sortir la femme de l'image et les femmes des ateliers. Si l'image précise n'est pas une source documentaire sur le travail des femmes, elle fournit néanmoins des indices sur le possible et le probable : l'artisan n'est pas inimaginable en femme.

Le réflexe de la mise à distance du réel, de la méfiance vis-à-vis des identifications, est sans doute le plus efficacement suggéré par F. Lissarrague à propos de la nudité des corps masculin représentés sur les images : «Les hommes ne circulaient pas tout nus dans les rues d'Athènes ", rassure-t-il (Frontisi-Ducroux, LisSARRAGUE, 2001, p. 52)! Autrement dit, la question que posent les images est celle du sens qui leur était alors donné plutôt que celle de leur conformité au quotidien de l'époque. Muni de ces précautions de méthode, on relèvera néanmoins la contribution extraordinaire des vases, stèles et offrandes à l'histoire des femmes, et donc à l'histoire sociale et à l'histoire du genre. Cette contribution concerne essentiellement les domaines économique et religieux, et touche à une question plus institutionnelle, voire idéologique : la règle implicite de l'anonymat des femmes.

\section{Archéologie des femmes}

11 De nombreux travaux ont mis depuis longtemps l'accent sur la capacité des femmes à déposer des offrandes en leur nom. Ces offrandes sont parfois prestigieuses surtout lorsqu'elles mobilisent des ressources économiques importantes. Dans un important article (KRON, 1996), Uta Kron a insisté sur le renouveau apporté par la documentation archéologique qui met à mal les conclusions des historiens sur les restrictions entourant la capacité des femmes à s'investir dans la vie économique. Particulièrement intéressant est le relief que Xénocrateia dépose vers 400 dans le sanctuaire qu'elle fonde en l'honneur du dieu Képhisos à Athènes (KroN, 1996, p. 78-80). L'offrande comporte une inscription partiellement lisible, en hexamètres, qui la désigne comme dédicante pour le dieu-fleuve Képhisos et les onze autres divinités qui lui sont associées. La fondation est liée à la protection et au soin qu'elle attend de ces divinités pour son enfant, Xéniades. Le relief présente une femme et son jeune fils, sans doute Xénocrateia et Xéniades, l'enfant tendant la main vers le dieu-fleuve Képhisos. Sur l'inscription, Xénocrateia se désigne comme fille et mère de Xéniades, ce qui signifie que l'enfant porte le nom de son grand-père maternel. Faut-il alors y voir une épiclère, une fille héritière car dénuée de frère et qui aurait, selon la loi, épousé un parent afin de prolonger la famille d'origine? L'hypothèse est possible mais non nécessaire. Xénocrateia est-elle seulement citoyenne ? Rien ne permet de le dire. Un tel document conduit surtout à dissocier la logique de la piété dans laquelle, manifestement, une femme peut se nommer et prendre des initiatives qui la rendent visible dans l'espace public, de celle, normative, des pratiques institutionnelles et masculines qui écartent les femmes de la sphère politique. Xénocrateia a suffisamment d'argent pour fonder son sanctuaire, elle fait travailler un ou plusieurs artisans pour l'élaboration du relief et 
l'inscription sur la pierre; elle semble avoir agi seule puisqu'elle se nomme seule et se représente seule avec son fils. Il est vrai cependant, comme le souligne U. Kron, que son offrande se situe dans un champ traditionnellement féminin, celui du soin prodigué aux enfants. Pourtant, plutôt que de distinguer des sphères d'activités masculine ou féminine, cet exemple incite à distinguer les types de discours.

\section{Silence et anonymat des femmes}

12 En effet, Christiane Sourvinou-Inwood a souligné à quel point il est important de distinguer les types de discours en fonction des types de sources dont on dispose (SOURVINOU-INWOOD, 2004). Elle rappelle ainsi que le discours historien se focalise sur certains aspects seulement de la vie sociale et que les stèles funéraires féminines, par exemple, s'inscrivent dans un contexte rituel spécifique qui n'est pas pris en compte par les sources littéraires. Reprenant la célèbre citation de Thucydide sur le silence attendu des femmes de valeur, un passage qui clôt l'oraison funèbre prononcée par Périclès (Guerre du Péloponnèse, II, 45, 2), l'auteure rappelle son contexte, celui du deuil de la cité rassemblée autour de ses morts, des défunts qui ont donné la vie pour la cohésion civique. Le silence recommandé aux femmes, la mesure attendue dans l'expression de leur émotion doit se lire, dit-elle, à l'aune du souci très précis de la cité en guerre qui, malgré ses deuils, doit conserver sa cohésion et ne pas se laisser déborder par des manifestations disruptives. Les femmes qui, dans le rituel, sont associées à l'expression émotionnelle du deuil sont donc les premières visées et doivent se contenir. D'un autre côté, en soulignant l'importance des figures féminines sur les stèles funéraires, C. Sourvinou-Inwood rappelle que là sont bien le lieu et le moment de leur présence, après les funérailles qui ont été organisées par le père, le fils, bref le mâle de la famille. Les stèles féminines expriment alors une présence réelle et nécessaire des femmes dans la gestion des affaires communes, qui sont également des affaires publiques puisque ces stèles sont bien en vue et qu'autour d'elles des cérémonies de commémoration prennent place.

Après Thucydide, les références sont nombreuses dans la littérature classique à cette qualité de discrétion des femmes que Plutarque associe au $\mathrm{i}^{\mathrm{er}}$ siècle avec leur réclusion : " la femme sage (sôphrona gunaika) doit au contraire se faire voir quand elle est avec son mari (andros), mais garder la maison et se cacher (kruptesthai) en son absence » (Traité, 11, 9). La vertu cardinale de la bonne épouse lui impose le silence en public et son corollaire, l'anonymat. Or les données archéologiques font apparaitre à Athènes même, et on l'a dit plus haut incidemment à propos de Xénocrateia, des noms de femmes dans des situations qui n'ont rien de honteux et sont au contraire parfois même prestigieuses. Les cas les plus connus sont sans doute ceux des prêtresses, et parmi elles Lysimachè (GEORGOUDI, [1993] 2003).

14 La règle du vertueux anonymat des femmes épouses et filles de citoyens est donc d'emblée entachée d'exceptions importantes que le livre récent de Joan Connelly tente, après d'autres (CONNELLY, 2007 ; SouRVINOU-INWOOD, 1995, GEORGOUdI, [1993] 2003), de recenser : les éléments apportés y sont cependant souvent très tardifs (essentiellement à partir du $\mathrm{II}^{\mathrm{e}}$ siècle avant notre ère) et renvoient à la fois à l'augmentation des données épigraphiques de la période hellénistique et impériale ainsi qu'à la pratique de plus en plus répandue de l'évergétisme féminin auquel plusieurs études ont été récemment consacrées (BREMEN, 1983 et 1996 ; BIELMAN, 2002), Bremen (1996) développant la thèse 
d'un évergétisme devenu plus familial que personnel, ce qui expliquerait qu'il intègre les femmes. En tout cas, rares sont les mentions de noms de prêtresses avant le IV siècle (LougovayA-Ast, 2006).

Dans cette approche archéologique, plus audacieuse est la démonstration de $\mathrm{S}$. Lewis qui voit dans la documentation des vases attiques des preuves que les femmes étaient impliquées dans des activités artisanales ou commerciales souvent mixtes (LEWIS, 2002, p. 91-116). Ainsi, et en sus de l'hydrie de Milan déjà évoquée, une série de vases présenterait selon elle des personnages, hommes ou femmes, en transaction. Elle discute plus précisément une pélikè attique de Madrid qui porte sur un côté un personnage féminin apparemment en train de laver du linge et sur l'autre un jeune homme tenant un petit sac à la main gauche et portant la main droite à ses lèvres. Contrairement aux interprétations qui analysent la scène comme un échange domestique entre mari et femme ou comme une invitation sexuelle adressée à une hétaïre, S. Lewis préfère y voir une transaction commerciale entre un client et une laveuse professionnelle, l'argument essentiel portant sur le petit sac du jeune homme qu'elle refuse d'associer, comme c'est souvent le cas, à un signe de commerce sexuel. G. Ferrari l'interprète quant à elle comme un sac d'astragales (ou osselets) associés aux scènes de jeux, de beauté et d'érotisme (FERRARI, 2002, p. 14-16). Par ailleurs S. Lewis croise ces vases, comme souvent dans son livre, avec des données de nature épigraphique qui convergent pour souligner la place des femmes dans le domaine économique. Ainsi au $\mathrm{VI}^{\mathrm{e}}$ siècle une offrande est déposée par Smikythè, une plyntria [laveuse] comme le dit l'inscription qui lui est associée. Au IV siècle, une dédicace aux nymphes est offerte par un groupe de laveurs (plynès) qui compte également deux femmes, Leukè et Myrrhnè (LewIS, 2002, p. 93-94); les comptes de construction des sanctuaires livrent également des noms de femmes travaillant sur les chantiers avec les autres ouvriers (FEYEL, 2006).

Globalement le recoupement de ces données engage à questionner la façon dont les historiens extrapolent les partages sexués dans les cités grecques à partir, le plus souvent, des seules sources littéraires (d'époque classique et/ou de tradition athénocentrée). Il n'est aujourd'hui plus possible de dire que les femmes restent à la maison à filer la laine, anonymes et protégées, et que les seules à travailler sont les prostituées. Beaucoup de fragments de céramiques trouvés sur l'agora d'Athènes portent des marques de propriété (LANG, 1974, p. 27-52; ROTROFF, LAMBERTON, 2006). Parmi eux, dix-neuf portent des noms féminins qui varient depuis les ethniques d'esclaves à des noms de citoyens. Plus significative encore, une coupe décorée avec des guerriers est remise comme prix à une femme nommée Mélosa à l'occasion d'un concours de travail de la laine (MILNE, 1945). Un kanthare béotien à vernis noir portant la mention "qu'elle le boive en entier " est offert par un mari à sa femme (WEBSTER, 1972). Ces deux exemples, cités par S. Lewis, vont à l'encontre de nos attendus : une femme remporte un prix féminin illustré par des guerriers, une femme est invitée par son mari à boire, comme dans un banquet - pratique réputée masculine. Contrairement aux mentions péjoratives qui accompagnent, chez les orateurs attiques, la description des activités commerciales notamment féminines, les personnages des vases que S. Lewis identifie ainsi ne semblent pas du tout dépréciés par les artistes.

17 Ce genre d'approche, lorsqu'elle est menée en tenant compte des objections de méthode signalées plus haut, renouvelle incontestablement le regard porté sur les relations entre les sexes dans le monde antique. Si les données s'enrichissent, il 
deviendra de plus en plus difficile d'affirmer que les femmes ont découvert la liberté ou, tout au moins, une certaine autonomie, seulement à l'époque hellénistique. On pourra toujours en revanche discuter pour savoir si le prestige et l'activité des femmes sont des faits de substitution qui pallient l'absence momentanée ou définitive d'un homme de la famille, ou pour identifier les lieux, moments et statuts qui encadrent ces activités. Sans verser dans une vision idyllique de la femme dans l'Antiquité, l'approche archéologique et documentaire permet incontestablement d'apporter des éclairages complémentaires de celui que fournissent les textes.

Pourtant les historiens du genre ne peuvent s'en tenir à ce constat qui ignore l'aspect symbolique du discours iconographique. Une autre tendance de l'interprétation, méthodologiquement à l'opposé, propose ainsi d'interpréter les images comme des métaphores du quotidien. Il s'agit alors, par une lecture serrée des différents sens que prend, cette fois plus souvent dans la littérature, tel mot, tel objet, tel acte, de scruter la façon dont l'image visualise des associations symboliques partagées par les artistes et leur public.

\section{Images et métaphores : représentations du féminin et du masculin}

Dans Figures of speech. Men and maidens in Ancient Greece, Gloria Ferrari offre l'exemple abouti d'une telle démarche (FERRARI, 2002). Elle inscrit explicitement son analyse dans les traces ouvertes par la linguistique et la sémiologie. Le discours des images produit des constellations d'objets ou de signes, des ensembles de codes qui, articulés aux personnages féminins ou masculins, constituent de véritables marqueurs de genre. Ces marqueurs renvoient à des systèmes de références partagés qui font que la plupart des gens en reconnaît le sens sans avoir besoin d'explication. Tout le travail des interprètes est de reconstituer les systèmes de genre dans lesquels sont impliqués les artistes, que ces systèmes symboliques relèvent de leur lieu de production ou bien, dimension qui échappe davantage à G. Ferrari et que S. Lewis souligne au contraire, de leur commanditaire.

\section{Marqueurs de genre : corps et objets}

Depuis longtemps les spécialistes des images ont souligné l'utilisation faite par les artistes de certains objets comme marqueurs de genre. Les femmes sont associées à la quenouille et au panier à laine, aux balles et aux osselets, aux fleurs, au coffre à bijoux, aux miroirs et aux alabastres qui contiennent le parfum qu'elles répandent sur leurs épaules. Les éponges et les aryballes qui contiennent l'huile du gymnase sont réservées aux scènes masculines, comme les armes, le casque, le bouclier, l'épée et la lance. Le strigile, ou racloir à toilette, est un objet plus partagé. Des études récentes s'attachent à réfléchir aux différenciations construites à partir de ces marqueurs. Ainsi Pierre Brulé s'interroge sur les connotations du bâton qui identifie le mâle, adulte et citoyen dans la céramique attique, et Hélène Bectarte sur celles du miroir représentés sur les stèles attiques (BRULÉ, 2006; BECTARTE, 2006). Jusqu'à présent l'étude la plus approfondie concernant cet "ustensile» féminin est celle qu'a menée F. Frontisi-Ducroux qui développe les implications psychologiques de l'association de la femme au miroir (FroNTISI-DUCROUX, 1997).

Dans un récent article, elle revient sur cette association à l'occasion d'une analyse du mythe fondateur de la peinture (Frontisi-Ducroux, 2007). L'invention de la 
représentation figurée est en effet souvent attribuée à une jeune fille (korè), « la fille de Dibutade». Selon Pline l'Ancien (Histoire Naturelle, XXXV, 151), la jeune femme, anonyme dans le texte, aurait tracé sur un mur de Corinthe les contours de l'ombre de son amant afin d'en conserver l'image. Son père Butadès (et non Dibutade comme le transmet la tradition à partir du $\mathrm{XvI}^{\mathrm{e}}$ siècle), potier à Sicyone, aurait transformé ce tracé en bas-relief en le fixant avec de l'argile. Il s'agit donc d'un mythe d'invention de la figuration plastique davantage que de celui de la peinture, deux arts considérés comme des techniques de construction de doubles à partir des doubles naturels fournis par les ombres. La tradition présente donc Butadès le potier comme l'inventeur de la coroplastikè, fabrication de figurines d'argile. Que vient faire la jeune fille dans un tel récit? Pour F. Frontisi-Ducroux, elle remplit ici un rôle symbolique, celui d'écranmiroir, qui reçoit l'ombre et la renvoie à son père, l'artiste-artisan. De ce point de vue, la jeune fille participe à des associations symboliques bien connues. En effet le rapport dressé dans le récit entre l'ébauche qui constitue le support de la création et la création elle-même est analogue au schéma par lequel les Grecs expliquent la reproduction sexuée: la femme fournit le support, matrice, sur lequel l'homme impose son empreinte pour produire des enfants. Davantage, le mot korè, jeune fille, désigne aussi en grec la pupille, à cause, dit Platon, de la silhouette que l'on voit dans l'œil de son prochain lorsque l'on s'y plonge (Alcibiade, 133a ; Phèdre, 255cd). La pupille est donc un réceptacle qui reçoit passivement l'image sous forme d'effluves qui s'y impriment mais est également un miroir qui renvoie activement le flux optique dans l'œil qui lui fait face. Dans la représentation antique, l'association de la jeune fille au miroir est riche d'implications symboliques : œil du créateur, pupille ou jeune fille, la fille du potier ne fait que recevoir l'ombre dont elle palpe le contour. Le père, créateur, produit l'œuvre d'art dont la fille a permis l'accouchement matériel.

Davantage que les objets, le corps est un marqueur de genre évident : dans la peinture à figures noires, alors que le corps masculin est traité en noir, les chairs féminines sont rehaussées en blanc (FrontISI-Ducroux, LISSARRAGUE, 2004, particulièrement p. 53-54). Lorsque tous les personnages sont vêtus de la même façon, c'est cette opposition blanc/ noir qui permet de différencier les sexes. Cette convention semble correspondre à une schématisation des pratiques sociales. L'homme est perçu comme passant son temps dehors, à la palestre, sur l'agora, dans les champs et à l'armée, halé par le grand air, contrairement à la femme qui est associée à l'intérieur de la maison. Cette convention répéterait donc une autre convention, littéraire et sociale, qui idéalise la vie des riches citoyens et de leur épouse censés se partager, selon les sexes, les espaces du dehors et du dedans.

En revanche, lorsqu'au $v^{e}$ siècle les peintres passent à la figure rouge, une telle distinction n'est plus opératoire et c'est le port du vêtement ou son absence qui distingue principalement les sexes. L'homme est représenté nu ou à peine vêtu tandis que la femme est le plus souvent couverte. Dans les cas très spécifiques où elle est nue, le critère de différenciation est parfois la taille, mais surtout la pilosité, le dessin de la poitrine et des organes génitaux. On constate cependant que sur les céramiques le pubis est souvent caché par le jeu des jambes. Quant aux seins, ils sont généralement conventionnellement dessinés de face, sans perspective, souvent orientés tous les deux dans la même direction, vers l'extérieur, le bas ou l'intérieur. S'agit-il d'une difficulté technique ? On peut en douter en constatant la maitrise dont les peintres attiques font preuve pour dessiner des nus masculins en des postures les plus diverses. Il semble 
plutôt que la différenciation sexuelle du nu est peu l'affaire des peintres qui dessinent des femmes aux épaules carrées, aux hanches étroites au-dessus de jambes très musclées. C'est donc un corps nettement masculinisé, représenté à partir des standards $\mathrm{du} n u$ athlétique et héroïque, qui sert de base au dessin du nu féminin dans la technique à figures rouges: le corps féminin est traité comme une variante du corps masculin.

En comparant au plus près les images d'hommes et de femmes, G. Ferrari insiste quant à elle sur un mode particulier de distinction à l'intérieur des catégories de sexe (FERRARI, 2002). L'examen des différentes pilosités lui permet d'affirmer que les hommes et les femmes sont nettement différenciés dans leur rapport à l'âge. La série masculine de l'hydrie de Phintias distingue ainsi quatre étapes masculines. Le jeune adolescent est représenté plus petit que les autres personnages et est absolument imberbe. Il côtoie un jeune homme en fleur, déjà de taille adulte mais sans barbe et qui porte simplement des premiers favoris qui descendent le long de son visage. La troisième étape est celle de la maturité représentée par un homme à la barbe et la moustache épaisses. La dernière est celle du vieil homme reconnaissable à la courbure de son dos et à la canne. Dans d'autres images, ce vieil âge correspond à celui de l'embonpoint, de la peau ridée et des cheveux gris. G. Ferrari relève d'autres signes en faveur de cette différenciation fine des âges masculins, cette fois dans la statuaire (FERRARI, 2002, p. 132-136). Ce sont des traces de peinture, parfois fugitives, qui sont ici destinées à rendre le fin duvet de la moustache, du menton ou des joues et qui marquent alors un premier âge adulte. Ces détails peuvent également être sculptés comme sur le visage du Cavalier Rampin où la jeune barbe forme comme un collier soulignant la structure du visage. La précision des peintres et des sculpteurs trouve un écho dans la richesse du vocabulaire grec pour désigner les différentes pilosités : ioulos pour les premiers poils qui poussent sur le visage, hupènè pour la nouvelle moustache, une première pilosité qui s'oppose à généion, qui désigne la barbe fournie de l'adulte. L'analyse souligne ainsi l'importance, pour les hommes, de l'étape de l'hèbè, la jeunesse, dite aussi l'hôra, la belle saison de l'éclosion où le jeune homme n'est plus un enfant (pais) et peut être un aimé (érômenos). Il est désigné désormais comme un hèbon ou un néos. Son entrée dans l'âge adulte du citoyen (anèr) se réalise par cette période liminale de deux ans environ, celle de la prime virilité qui coïncide avec ce que les Athéniens nomment l'éphébie.

Inversement, argumente G. Ferrari (FERRARI, 2002, p.176-178), les filles passent directement de l'âge enfantin, rarement marqué par la première poitrine mais plutôt par une taille plus petite, à celui de l'épanouissement sexuel. La jeune fille, l'épouse et la mère ne se distinguent généralement pas. Seule la très vieille femme, ridée, aux cheveux blancs et au dos courbé signale un changement important, celui de la physiologie. Jeunes filles et femmes se confondent alors, comme le montre la scène des héroïnes argiennes en famille: les deux sœurs Hélène et Clytemnestre sont accompagnées de la jeune Iphigénie, fille de Clytemnestre, dont rien ne signale la différence d'âge. Le phénomène est également remarquable sur les stèles funéraires où il est fréquent qu'une grand-mère ne se distingue pas d'une mère ${ }^{1}$.

Les artistes donnent ainsi à voir de vrais systèmes de genre : le masculin articulé autour de quatre âges, le féminin autour de seulement trois âges. Seul le masculin développe l'étape privilégiée de la jeunesse adulte qui concentre les qualités de beauté physique, d'attraction érotique et de capacité athlétique et guerrière. Le corps fonctionne comme les objets que le peintre associe aux sexes : différemment représenté, il contribue à la 
construction des systèmes de genre. Les masculinités sont plurielles, les féminités aussi, mais le masculin et le féminin s'opposent globalement comme le nu s'oppose au vêtu, comme le miroir s'oppose au bouclier, comme le panier à laine s'oppose à la panoplie guerrière (Aristote, Rhétorique, 1361A1-7). Le thème est d'ailleurs explicitement illustré dans le mythe d'Achille réfugié à Skyros chez les filles du roi Lycomède (Apollodore, Bibliothèque, 3.13.8; WALDNER, 2000 ; FERRARI, 2002, p. 89).

\section{Choix picturaux : les types et les absences}

Les peintres ne décrivent pas plus le réel qu'ils ne répètent les textes. Le discours des images produit lui-même, de façon autonome, des constellations de sens. Les artistes font en effet des choix et ignorent par exemple la situation de la naissance qui est pourtant fondamentale pour le passage d'une jeune fille au statut de gunè, épouse mais surtout mère (LEWIS, 2002, p.58). Ils ignorent également leur réelle activité de production. Le panier à laine est davantage un marqueur de féminité, quoi qu'en dise $\mathrm{S}$. Lewis, inséré dans des scènes de beauté et de toilette, qu'une référence au travail luimême. Les artistes ignorent les relations amicales ou sexuelles des femmes (BOEHRINGER, 2007, p. 143-157). Leurs choix dessinent des configurations spécifiques : les femmes sont présentes en tant qu'épouses, mères de guerriers, célébrantes dans les rituels, mais sans précisément découper les viandes ni s'affairer à la cuisine. Certaines statuettes de femmes âgées sont même interprétées, selon une suggestion difficile à démontrer (LEWIS, 2002, p. 56-58), comme les signes que certaines vertus apotropaïques étaient prêtées aux femmes, considérées comme des soutiens naturels dans le monde des morts. C'est ainsi une image publique de la femme qui est donnée à voir. Il en est de même pour l'homme, représenté en athlète, symposiaste, sacrifiant à l'autel, guerrier. Ni les uns ni les autres ne correspondent réellement, pas plus que ce que décrivent les textes, à l'ensemble du vécu ni même à ce que les producteurs et commanditaires avaient sous les yeux.

La preuve la plus évidente de cette capacité des artistes à développer un langage propre tient dans l'absence, sur les images, de l'indication de statut des personnages. C'est particulièrement le cas dans les scènes au lavoir ou à la fontaine, scènes de travail où l'on attendrait que soit spécifié s'il s'agit d'esclaves ou de citoyens et de citoyennes. S. Lewis commente à ce propos (LEWIS, 2002, p. 79-80) une coupe béotienne montrant sur une face trois femmes identifiées avec des noms, Kodoma, Euarchia et Eupharia. Les deux premières s'activent à moudre (du grain?) alors que la troisième, debout, les regarde faire, la quenouille à la main. La quenouille étant souvent un code de féminité accomplie, on aurait tendance à identifier sur cette face deux esclaves, Kodoma et Euarchia, travaillant sous le regard de la maitresse de maison, Eupharia. Pourtant, sur l'autre face, c'est Euarchia qui se lave les cheveux au-dessus d'une vasque. Elle est assistée dans cette opération par Euphrosuné qui lui verse l'eau sur la tête, une attitude jugée plutôt servile. Cette scène de toilette, qui pourrait renvoyer au thème de la célébration de la beauté féminine, s'accorde mal avec le possible statut d'esclave d'Euarchia. Il est donc impossible et vain de tenter de démêler les statuts des personnages auxquels l'artiste ne prête pas la moindre attention.

Pourtant, dans la mesure où les peintres ont parfois usé de tatouages, dessinés sur les bras et les jambes, pour indiquer l'origine thrace de certains personnages, ils auraient trouvé un système de codage pour identifier les esclaves, si le besoin s'en était fait sentir. Or ni les cheveux courts ou remontés en arrière, ni le port d'amulettes ne sont 
des signes clairs (SHAPIRo, 1992). S'agit-il d'une volonté consciente de brouiller les catégories (BEARD, 1991) ? Ou bien est-ce un indice que, dans le monde grec, la seule catégorie finalement pertinente pour distinguer les individus est celle du sexe?

\section{Corps et sexualité : césure des sexes et institutions de genre}

\section{Nudité masculine et vêtements féminins}

La question de la nudité masculine héroïque alimente un débat depuis la fin du XVIII ${ }^{\mathrm{e}}$ siècle avec Winckelmann (Pоттs, 1994) sur lequel on ne présentera ici que l'interprétation très convaincante qu'en a récemment donnée G. Ferrari (FERRARI, 2002, p. 119-122). Elle rappelle que le port du manteau est un élément important dans les scènes de séduction : le manteau est alors porté soit par la femme, soit par le garçon, soit par les deux individus qui se font face. Le costume qui enveloppe le corps lui semble une métaphore directe de l'aidôs, à la fois modestie, honte et respect de l'autre. L'acte sexuel lui-même trouve une formulation conventionnelle lorsque l'union de deux individus dit se réaliser sous la couverture, ou le manteau. Pour une femme, ce vêtement est comparable, précise G. Ferrari, à l'armure qui protège le guerrier. Or, poursuit-elle, la destinée d'un garçon est justement de quitter le manteau pour montrer qu'il est devenu un homme.

31 Dans différents rituels, notamment à Sparte, les jeunes exhibent ainsi leur nudité et ces rituels sont rapprochés par G. Ferrari du récit que donne Nicandre de Colophon de la transformation sexuelle de Leucippé. Lampros, un Crétois, époux de Galatée, menace de tuer l'enfant qui doit leur naître si celui-ci s'avère être une fille (Antoninus Liberalis, Métamorphoses 17.6). Galatée accouchant d'une fille décide alors de la faire passer pour un garçon, Leucippos. Leucippé-Leucippos grandit et devient tellement magnifique que Galatée redoute que sa ruse ne finisse par être découverte. Elle trouve alors refuge au sanctuaire de Létô Phythia et supplie que la déesse de la croissance change sa fille en garçon. C'est ainsi que Leucippé devient un admirable jeune homme qui n'a pas honte de retirer son vêtement pour exhiber sa nouvelle masculinité. À Phaestos en Crète, la fête des Ekdusia pourrait célébrer ce moment mythique où la jeune fille aux apparences de garçon a retiré (exedu) son péplos. Si l'on en croit la répartie de Philokléon dans les Guêpes d'Aristophane, c'est avec gourmandise que certains magistrats examinent les jeunes recrues de 18 ans qui prétendent à l'admission dans le dème de leur père (Aristophane, Guêpes 578). Ceux-ci pourraient avoir été soumis, même à Athènes, à un rite de dévoilement destiné à montrer à leurs concitoyens qu'ils étaient conformément formés. L'abandon ritualisé du vêtement met en scène et magnifie, comme s'il s'agissait d'un changement de sexe, l'entrée des garçons dans la phase de l'hèbè, le passage du jeune encore enfant (pais) à l'âge du jeune homme (néos). Il s'agit très précisément d'un changement de genre (FERRARI, 2002, p. 123).

C'est armée de cette nouvelle analyse que G. Ferrari interprète le type du kouros qui alimente le débat sur le nu grec. Au lieu de traiter la question de la nudité masculine par le biais de la vulnérabilité/invulnérabilité d'un guerrier qui ne craint pas le corps à corps (ainsi BASSI, 1998, p. 100-104; et bien avant: BONFANTE, 1989), elle démontre que cette nudité vise à afficher le statut même de l'adulte et du citoyen, celui qui est réputé être en pleine possession des qualités de l'anèr. Dans ce cadre-là, on comprend mieux la honte faite à ceux qui se comportent mal vis-à-vis des normes civiques: les dévêtir signifie montrer à tous qu'ils ne tiennent pas le rang imposé par leur corps. Ainsi les 
célibataires à Sparte, selon Plutarque, sont mis à l'amende et obligés de se montrer nus, sur l'agora, en plein hiver (Vie de Lycurgue, 15, 1-2). En déshabillant celui qui ne respecte pas ce qui est progressivement devenu une des normes de la masculinité spartiate, le mariage et l'engendrement d'enfants, il s'agit de confronter un comportement défaillant à un corps, masculin, et aux obligations de son sexe.

Il en est de même, à mon sens, avec l'épisode de l'Iliade lorsque le lâche Thersite est menacé par Ulysse de se faire arracher ses vêtements (Iliade, II, 246-264). Il ne s'agirait pas, comme il est parfois avancé (BASSI, 1998, p. 134-135), d'assimiler le lâche, en le dénudant, à une femme qui serait, car sans armes, évidemment toujours vulnérable. Il s'agirait plutôt de ricaner sur le décalage entre les prétentions à la masculinité héroïque, prétentions associées au sexe et donc au corps masculin, et le comportement indigne que Thersite manifeste. Comme les célibataires spartiates mais pour des raisons liées aux normes héroïques de l'Iliade davantage qu'aux normes de paternité de Sparte, Thersite est indigne de son corps masculin et cette indignité doit être manifestée publiquement.

La femme en revanche ne passe pas par cette étape du dévoilement public qui afficherait à tous qu'elle est devenue une vraie femme, mature et productrice. De ce point de vue, son genre est d'emblée assimilé à son sexe, celui de sa naissance ; elle n'en change pas. Le rituel du dévoilement (anakalyptèrion) de la mariée qui pourrait fonctionner comme une correspondance au rituel du dévoilement du jeune homme n'a rien à voir avec la thématique du vêtement et de la nudité (FERRARI, 2002). Les anakalyptèria que les textes évoquent parfois correspondraient, selon Ferrari, au dévoilement de la jeune fille qui a été promise de façon privée à un autre homme. Il s'agit ce jour-là non de la dénuder ni même de dévoiler son visage, mais de la sortir de la maison et de la promener pour montrer à tous qu'elle quitte un lieu pour un autre. Si elle garde son manteau sur les scènes de mariage représentées par les peintres, la main souvent portée à la tête comme pour retenir un voile, c'est bien qu'elle reste toujours couverte. C'est la transaction qui a précédé, celle de l'enguè [fiançailles], qui porte l'explication de la métaphore du dévoilement : en étant promise à un homme, la fille a été retirée de la circulation, autrement dit des échanges. Placée comme un trésor sous la terre, elle est depuis cet engagement comme un bien placé à l'abri des convoitises. Dans cette interprétation séduisante mais discutable (FERRARI, 2002, p. 179-200, surtout p.186-190 ; FERRARI, 2004; GHERCHANOC, 2006), l'anakalyptèrion désignerait alors le moment de la sortie de la fiancée, au grand jour, toujours voilée puisque le voile ou le manteau est signe de sa valeur.

La nudité héroïque, expression d'une andréia [bravoure] que les Grecs localisent dans le corps masculin et pensent ainsi comme naturelle, a également donné lieu à une fine analyse qui souligne la proximité entre la représentation grecque du corps masculin, constitué de fibres et de muscles (le terme grec neuron est un des noms du membre viril) et le verbe néô qui signifie filer (IRIARTE, 2007). Sans aller jusqu'à supposer une féminisation des corps masculins, l'hypothèse a l'intérêt de rappeler combien la nudité athlétique, dont le tissu musculaire était conçu comme le résultat d'un tissage, apparaissait aussi aux yeux des Grecs comme le résultat d'un travail et d'un exercice régulier, bref comme relevant de l'artifice. Le corps idéal exprime alors le genre au-delà du sexe ou plutôt, en créant du masculin, il sur-interprète le corps. C'est cette différence entre genre (social) et sexe (physique) qui explique que parfois le comportement (domaine du genre) ne soit pas en adéquation avec ce que certaines 
normes réclament du sexe. On l'a dit avec Thersite et les célibataires spartiates en défaut de masculinité, mais il en est a contrario de même des femmes guerrières ou des femmes courageuses qui font preuve d'andréia, malgré leur sexe.

F. Lissarrague a montré qu'à la guerre la femme peut être représentée d'une façon proche de l'hoplite (LISSARRAGUE, 1990, p. 32-34). Il est d'usage de parler d'Amazones pour ces femmes qui apparaissent pourtant comme des combattantes isolées. Elles se distinguent particulièrement, dans leur fonction, des Amazones décrites par les orateurs athéniens et sculptées sur les frontons et les métopes des temples édifiés après les guerres médiques (LORAUX, 1981b, p.147-150). Là, sur les métopes ouest du Parthénon et sur le bouclier d'Athéna Parthénos à Athènes comme sur les métopes du Trésor des Athéniens à Delphes, les Amazones classiques se constituent en paradigme des Perses redoublant le clivage grec/ barbare du clivage masculin/féminin. Puisque les femmes guerrières isolées, qui s'identifient souvent graphiquement aux hoplites qu'elles combattent, appartiennent à une tradition iconographique plus ancienne, il est plus prudent de les désigner comme des femmes guerrières plutôt que comme des Amazones, terme qui renvoie à la construction idéologique de l'altérité dans l'Athènes classique (BLOK, 1995). Or F. Lissarrague souligne que ces héroïnes de guerre, contrairement à leurs homologues masculins, ne sont jamais représentées nues. L'hoplite, conclut-il, est donc un type de guerrier qui peut rapprocher les hommes des femmes, qui distingue toujours les Grecs des Perses (ceux-ci ne sont jamais représentés en hoplites), mais la nudité héroïque est un code qui, lui, n'appartient qu'à l'homme grec.

Examinons-en deux exemples. Le premier est tiré d'une petite série bien connue, celle des reliefs en bronze décorant les lanières de cuir des boucliers hoplitiques déposés en offrandes à partir du vil siècle à Olympie. De la première moitié $d u v^{e}{ }^{e}$ siècle, un relief argien présente une femme, à gauche, vêtue d'un chitôn [tunique] court et dont l'inscription «PEN » suggère qu'il s'agit de Penthésilée. Elle est opposée à celui qu'on identifie dès lors à Achille et qui porte une courte cuirasse pour protéger son torse (ВLок, 1995, fig. 2b). La scène renvoie aux récits héroïques de la lutte d'Achille contre la reine des Amazones, des guerrières valeureuses et alliées malheureuses des Troyens.

Le second exemple est beaucoup moins connu: il s'agit d'un aryballe protocorinthien trouvé dans la nécropole de Léchaion à proximité de Corinthe et daté de 690-680 environ (ЕLIOT, 1968, pl. 102). Éditée en 1968, l'image a surtout retenu l'intérêt des archéologues travaillant sur l'armement et en particulier sur la date de l'apparition du bouclier de type hoplitique. En effet il apparaît au bras du personnage principal. Cette figure étonne, d'ailleurs : elle porte une robe à damiers alors que toutes les autres figures sont nues ou juste revêtues d'une courte cuirasse. Les éditeurs y voient le signe qu'il s'agit d'Athéna au combat. Cette identification les conduit à identifier la scène avec une gigantomachie, le combat mythique qui oppose les dieux et les Géants. Pourtant les personnages masculins combattant aux côtés de la figure vêtue sont munis d'arcs et de flèches. À l'opposé, les dits Géants sont représentés avec épée et lance, comme des hoplites, si ce n'est qu'ils portent un long bouclier. Il serait donc peut-être plus prudent de laisser l'interprétation ouverte. Dans ce combat héroïque, le vêtement porté par le personnage principal introduit une distinction de prestige et/ou de sexe. Sa valeur se mesure à sa taille, sa centralité sur l'image et la décoration recherchée de sa robe. Puisque des personnages féminins en armes ont pu être représentés dans l'iconographie archaïque, l'hypothèse d'une combattante dont le sexe serait codé par le 
vêtement n'est pas à exclure. L'intérêt de l'image serait de montrer une telle combattante non pas dans un combat isolé, comme sur les séries de lanières de bouclier, mais cette fois alliée à des combattants masculins. Par ailleurs, elle est ici représentée non en vaincue mais menaçante pour son adversaire. La nudité ne sert donc pas à coder l'hérö̈sme victorieux, mais bien le sexe: une femme vêtue et guerrière accéderait à une valorisation équivalente à celle d'un guerrier ${ }^{2}$.

Les rares femmes armées, lorsqu'elles ne sont pas des Amazones en bandes et vêtues à l'orientale, pourraient donc bien, aux yeux des Grecs, rester des vraies femmes (il n'y aurait nulle transgression), non pas des femmes comme les autres mais des femmes héroïques, admirables pour leur andréia, comme les héros masculins. Après tout, des déesses ont montré l'exemple. Et si l'andréia est une notion qui joue sur des effets physiques, souffle impressionnant et puissance musculaire (thumos, alkè), ces qualités ne sont pas toujours et nécessairement sexuées (BASSI, 2003, p. 33-34).

Le corps sexué est bien le lieu d'une radicale différence, la différence sexuelle, entre les individus. Il serait donc probablement absurde pour les Grecs de vouloir représenter des femmes héroïques nues puisque c'est le corps masculin qui codifie l'héroïsme. Cela ne signifie pas qu'une femme ne peut être héroïque et revêtir l'andréia de ses pairs, y compris dans le champ de la guerre. Il n'y a ici nulle transgression mais plutôt des exceptions qui expriment la logique même du genre : il s'agit de normes culturelles qui sont par définition sujettes à variations. Parfois la détermination du genre prime sur celle des sexes: se comporter vaillamment prime sur être une femme. L'image des femmes guerrières conduirait alors à relativiser la portée du nu héroïque : si les héroïnes peuvent être représentées en hoplites mais non dénudées, ce n'est pas parce qu'elles sont moins valeureuses que les hommes ou que la valeur ne s'exprime qu'au masculin, mais parce qu'elles sont des femmes et que dans le système de représentation des Grecs la nudité féminine ne codifie pas l'héroïsme.

\section{Hommes et femmes : genre et sexualité}

41 Alors que la nudité féminine n'est pas devenue une représentation conventionnelle avant la deuxième moitié $d u \mathrm{IV}^{\mathrm{e}}$ siècle et la fameuse Aphrodite de Cnide réalisée par Praxitèle, G. Ferrari se demande pourquoi les représentations de déesses nues dites de type oriental, souvent réalisées sur terres cuites, sont devenues acceptables pour les Grecs (FERRARI, 2002). La démonstration est, quoique fragile, très intéressante en ce qu'elle mobilise la figure de la déesse Aphrodite Ouranienne qui, selon elle, renverrait, bien avant son éloge par Platon, à une homosexualité masculine spécifique.

G. Ferrari soutient que la déesse nue de type oriental est comprise comme portant les prérogatives que les Grecs attribuent à l'Aphrodite Ouranienne et pour le démontrer, elle inclut dans son analyse le dossier malheureusement bien peu épais des déesses nues bisexuées. À Chypre par exemple, Aphrodite est honorée comme une créature au corps féminin, portant une robe, mais pourvue d'organes génitaux masculins. Un culte à une Aphrodite barbue est attesté en Pamphylie. Ces traits esthétiques et culturels croisant les genres trouvent probablement des correspondants en Grèce. Ainsi une terre cuite corinthienne du $\mathrm{VI}^{\mathrm{e}}$ siècle représenterait Aphrodite Ouranienne émergeant des bourses d'Ouranos : la figure porte une robe sur des formes féminines mais sa barbe signale une masculinité adulte. Selon G. Ferrari (FERRARI, 2002, p. 109-110), nous serions ici en présence de témoignages illustrant la sexualité masculine civique, si l'on peut 
dire. Il s'agirait d'une sexualité d'hommes qui se plairaient à exclure les femmes du processus de la reproduction, le scrotum masculin d'où est issue Aphrodite remplaçant l'utérus féminin. Par ailleurs, la barbe signalerait la capacité de reproduction propre aux hommes adultes. Le discours de Diotime, dans le dialogue platonicien du Banquet, utilise en effet la métaphore de l'accouchement pour associer l'émission de sperme à un acte magique d'engendrement auprès de l'érômenos. Celui-ci va produire de belles choses à défaut de beaux enfants (Banquet 209d; BOEHRINGER, 2007, p. 100). L'Aphrodite Ouranos, que Platon oppose à l'Aphrodite Pandèmos, divinité du désir sexuel quelque en soit son orientation, patronne les relations des hommes entre eux (Banquet 180d-181c). Elle serait la destinataire, pour les Grecs, de ce type de représentation de déesses nues et barbues.

L'hypothèse, qui mobilise à la fois le champ du religieux, de la pensée platonicienne, et de la sexualité, nourrit fondamentalement la thèse principale de G. Ferrari sur l'existence en Grèce ancienne d'un troisième genre, celui des jeunes hommes. Le corps du néos ou de l'éphèbe, l'homme dans sa hôra [belle saison], attire à lui le désir des autres hommes: il est comme les kouroi, déjà mature mais encore au seuil de l'âge adulte. Il porte parfois des rubans dans les cheveux, des colliers ou boucles d'oreilles qui le renvoient à la sphère de la beauté apprêtée des jeunes filles (FERRARI, 2002, p. 115-124). Son érotisation se marque dans ses cuisses pleines, ses joues arrondies, ses tétons prononcés. En ce sens il peut rejoindre les femmes du banquet puisqu'il fait parfois partie, comme elles, des compagnons et compagnes qui accompagnent les hommes barbus allongés sur les lits (Schmitt-Pantel, 2003, p. 83-95). Pourtant sa situation est différente de celle des femmes, argumente G. Ferrari, en ce qu'il est précisément actif dans sa sexualité (contra HALPERIN, [1990] 2000). G. Ferrari utilise ici les conventions grecques d'une érotique qui opposeraient deux aspects, passif et actif, qu'elle assimile à l'opposition entre la sexualité des femmes hétérosexuelles, passive, et la sexualité masculine adulte valorisée, active.

La relation entre l'érômenos [l'aimé, jeune homme] à l'éraste [l'amant, plus âgé] n'a, il est vrai, rien à voir avec une relation hétérosexuelle : le jeune homme n'est jamais assimilé à une femme et la relation elle-même ne donne jamais lieu à une analogie avec le mariage. Le rapport qui unit les deux partenaires est certes soumis à l'érôs [amour], mais gouverné par une philia [amitié] réciproque. La figure fondatrice de cette amitié amoureuse qui lie les citoyens est celle d'Harmodios et Aristogiton, les deux amants qui ont agi sous la direction de la philia érotique, justement contre les tyrans qui abusent de leurs partenaires et tentent de les brutaliser. Le groupe de Critias et Nésiotès qui survit dans une copie romaine le montre. Harmodios est représenté en kouros, imberbe, et pour le moins actif; il brandit l'épée à un âge que Thucydide (VI, 54. 2) décrit comme celui de l'éclat et de l'épanouissement, et qui correspond à l'âge des héros tel Achille (FERRARI, 2002, p. 130). L'érôménos n'est donc plus un enfant. Il n'est pas un mineur qui ferait tomber son séducteur sous les coups de la loi contre l'outrage (hubris). La réciprocité de la relation valorisée nécessite le consentement des deux partenaires. Il n'est pas non plus ce dépensier (d'argent et de sperme) que G. Ferrari assimile improprement à un efféminé : le kynaidôs des Grecs est plutôt le déviant social et sexuel qui se positionne à l'opposé de la norme du bon comportement masculin, celui, grosso modo, de l'hoplite (WINKLER, [1990] 2005). L'étape de la jeunesse masculine n'est donc pas celle d'une identification des genres, masculin et féminin, ni celle de leur brouillage ou de leur superposition. Elle correspond, selon G. Ferrari, à un autre genre, masculin, 
qui se décrit le plus parfaitement dans le corps mâle héroïque et cette fois-ci explicitement désirable.

À ce point de l'argumentation, le raisonnement glisse et évite bien des obstacles : Comment se fait-il que les représentations de partenaires masculins de taille identique ou quasi identique, illustrant donc la thèse de l'amour idéal réciproque des deux adultes consentants, disparaissent globalement après $500 \mathrm{av}$. J.-C., lorsque les peintres passent à la figure rouge ? Comment expliquer ces scènes $d u v^{e}$ siècle mettant face à face des personnages bien inégaux, où l'éraste introduit son sexe entre les cuisses du "petit» garçon? Faut-il y voir, comme le dit G. Ferrari, l'expression d'un pur fantasme? Et enfin que dire de la sexualité hétérosexuelle? Faut-il reprendre les oppositions quelque peu systématisées entre passivité féminine et activité masculine? Que dire de la fellation qui met en jeu en réalité une femme active et un homme passif ? D'importantes critiques, que G. Ferrari a écartées de son analyse, ont été apportées depuis plus d'une dizaine d'années à cette association souvent trop facilement réalisée entre la polarisation assez théorique passivité/activité et le couple femme/homme (WINKLER [1990] 2005) ; DAVIDSON, 1997).

D'autres séries de travaux s'attachent quant à eux à relever l'intégration des femmes dans les relations de réciprocité qui caractérisent idéalement le monde des citoyens. S. Lewis traque dans cette perspective les échanges de regards ou d'objets qui soulignent la recherche du consentement féminin, cherchant ainsi à réviser la description pessimiste donnée des femmes antiques (LEWIS, 2002, p. 172-209). Elle souligne que les femmes peuvent être valorisées pour d'autres tâches que les seules tâches sexuelles où elles seraient, dit-on, uniquement belles à voir et objets de plaisirs. Ainsi les musiciennes qui ont longtemps passé pour des prostituées ressortent de son enquête comme des professionnelles auxquelles on fait appel pour leur talent, leurs compétences, non pour leurs charmes ${ }^{3}$. Surtout elle met en avant des vases qui représentent une nudité féminine qu'elle interprète sans a priori négatif et en montrant que l'équation généralement admise selon laquelle une femme représentée nue est une prostituée doit être révisée. La nudité chaste de l'Aphrodite de Cnide est une nouvelle convention qui ne doit pas renvoyer toutes les autres figures de nudité féminine à des scènes de pornographie. Prenons le cas de la coupe attique à figures rouges du peintre de l'agora, Chaireas, trouvée dans un dépôt sur l'agora d'Athènes : on y voit une femme qui tient une couronne devant un autel. Elle est nue vêtue du seul sakkos qui lui couvre les cheveux et porte des boucles d'oreilles. S'agit-il d'une hétaïre, autrement dit une courtisane? S'agit-il d'un culte spécifique? La nudité ne semble pas ici un critère majeur, en tout cas elle ne paraît ni dévalorisante ni masculinisante (LEWIS, 2002, p. 103). Le cas est peut-être encore plus net avec l'hydrie de Copenhague du Peintre de Washington. Une femme nue se tient debout et travaille au fuseau devant une femme vêtue assise devant elle. S. Lewis montre que ce vase appartient à une série attribuée au même peintre et réalisée entre 440 et 430 av. J.-C. Tous ces vases montrent des femmes dans une activité de toilette ou d'habillage, souvent avec un Éros. S. Lewis propose donc de les relier au contexte rituel du mariage, incluant la toilette et l'habillage et, au lieu de lire ces images comme des scènes de bordel, elle préfère insister sur la mise en avant de la séduction de la mariée dont la nudité serait un aspect particulier (LEWIS, 2002, p. 104). Par ailleurs, la courte série des femmes nues au banquet suscite des hypothèses intéressantes. S'agit-il, comme dans le cas du psykter conservé au Musée de l'Hermitage, de scènes de parodie, ici des femmes spartiates qui, aux yeux des 
Athéniens, joueraient des rôles d'hommes (FERRARI, 2002, p. 20)? Ou bien s'agit-il d'attestations de possibilités sociales, celles de femmes effectivement au banquet dans des situations d'autorité et de plaisir, comme le sont habituellement les hommes (LEWIS, 2002, p. 114-115)?

Ces tentatives de débusquer un autre rapport aux femmes, plus positif, relèvent-elles d'un retour en arrière caractéristique d'un anti-féminisme latent comme il est parfois suggéré (DEMAND, 2002, p. 35 ; contra FoXHALL, 1997) ? On refusera d'entrer dans un tel débat qui relève de la sociologie contemporaine pour se demander plutôt si la question du genre, en renouvelant les études sur les femmes, n'aboutit pas à interroger l'institution des normes de genre, leurs contournements et leurs sphères d'applications. Le croisement des types de sources, l'apport des images et de l'archéologie de façon plus générale imposent de relativiser la part des discours normatifs ou tout au moins de repérer leur caractère idéologique pour mieux réfléchir sur la coexistence des pratiques.

Sandra Boehringer a ainsi précisément distingué les niveaux de validité des discours afin de mieux interpréter les silences et les non-dits des textes ou des images en ce qui concerne un domaine longtemps ignoré, celui de l'homosexualité féminine (BOEHRINGER, 2007). Reprenant le mythe de l'Aristophane de Platon, présenté dans le Banquet, elle en souligne à la fois la proximité avec le discours très socratique de Diotime et la radicale différence : le propos d'Aristophane est préoccupé par le lien individuel qui unit les individus bien plus que par la production du Beau. Or les liens individuels touchent aussi bien les hommes que les femmes puisque tous sont issus de trois êtres originels, l'homme-homme, la femme-femme et l'être androgyne, homme-femme. La coupure de ces trois êtres doubles et bisexués en deux moitiés isolées, les individus à un seul sexe que l'humanité connaît, crée dans le mythe la dynamique d'un désir orienté vers la recherche de la moitié perdue. L'érôs identique qui produit l'attirance entre les individus se tourne pour les uns vers les gens de même sexe, homme vers homme ou femme vers femme, et pour les autres, issus de l'être androgyne, vers les individus de sexe différent. Ainsi il n'y pas, selon Aristophane, deux sexes et deux sexualités, la sexualité hétérosexuelle et la sexualité homosexuelle masculine, mais en réalité, souligne S. Boehringer, un troisième type de comportement érotique, peu documenté car il n'a aucun impact sur la vie des hommes à Athènes : celui des femmes entre elles.

Quant à l'iconographie des relations homoérotiques et au statut iconique de l'olisbos, ce phallus postiche très souvent considéré comme un marqueur d'homosexualité féminine, S. Boehringer, reprenant l'ensemble des images, n'a pas de mal à montrer qu'il apparaît dans des contextes d'hétérosexualité (ce qui est confirmé par l'usage littéraire du terme chez, cette fois, l'auteur comique Aristophane), associé à d'autres objets phalliques de toutes formes, et est donc davantage un symbole de virilité qu'un " ustensile» de lesbiennes (BoEHringer, 2007, p.146-150). Comme d'autres l'ont également souligné (VILLANUEVA-PUiG, 2000 et 2004), les relations des femmes entre elles n'intéressent pas les peintres: le sexe féminin est exceptionnellement dessiné, contrairement au sexe masculin et aux jeux qui l'entourent, ainsi les fellations, les positionnements variés du membre en érection ou l'acte de copulation. L'auteur interprète les rares scènes d'attouchement de femmes entre elles comme des scènes de toilette, notamment des scènes d'épilation et d'érotisme, qu'il faut relier, encore une fois, à l'un des nombreux modes de représentation de la beauté féminine. Les protagonistes de ces scènes sont en effet soit des femmes, soit une femme et un satyre. 
Il s'agirait alors d'une utilisation conventionnelle du satyre pour faire pénétrer un regard et une main masculine dans des espaces et des moments où il est normalement jugé inconvenant de les trouver (LISSARRAGUE, 1987 et 1998 ; BOEHRINGER, 2007, p. 151).

Les artistes fournissent à l'histoire du genre une matière aussi importante que celle apportée par les tragédies athéniennes, tout aussi investies par l'opération de la mimèsis . Les femmes et les hommes représentés sont des images du féminin et du masculin, des féminités et des masculinités, avec des déclinaisons qui reprennent la plupart des situations sociales connues ou rêvées par les peintres et leurs commanditaires. Leur mise en relation avec des documents d'autres natures, archéologique ou littéraire, permet souvent de déceler et de comprendre le jeu métaphorique en cause, d'apprécier le référentiel qui sert de base à la communication avec le public. Comme avec la tragédie ou avec l'analyse du divin (qui opère également dans le champ des représentations), le piège principal est celui de l'illusion: illusion de voir du réel, illusion de transformer la représentation en nouveau réel, mais illusion également de traiter la représentation en fiction.

Les images délimitent les contours d'un féminin idéal : vêtu, travaillant la laine, beau à voir car apprêté par la toilette, les bijoux, les fards, encourageant le départ des garçons à la guerre, agissant dans la sphère cultuelle, protégeant les enfants dans l'au-delà. L'esthétique du masculin est corporelle, athlétique et juvénile, associée à l'âge qui révèle des promesses d'accomplissement. Ces deux genres, typifiés, n'épuisent pas la palette du peintre et celle des comportements: ils ne contraignent ni le réel ni les symboliques du féminin et du masculin. Ils soulignent cependant la forte asymétrie entre un masculin idéal codifié par les peintres dans le corps nu et ainsi dans le sexe masculin, et un féminin idéal associé quant à lui à des techniques et un travail: particulièrement celui de la laine. Les artistes, de ce point de vue, et parce qu'ils dessinent des corps, ont efficacement naturalisé le genre et offrent aujourd'hui un matériel incomparable pour son étude.

\section{BIBLIOGRAPHIE}

- BASSI, 1998 : Karen Bassi, Acting like Men. Gender, Drama, and Nostalgia in Ancient Greece, Ann Arbor, 1998.

- BASSI, 2003 : Karen Bassi, « The Semantic of Manliness in Ancient Greece », dans Karen Bassi éd., Andreia Studies in manliness and courage in Classical Antiquity, Leyde/Boston, 2003, p. 25-58.

- BEARD, 1991 : Mary Beard, « Adopting an approach II », dans Tom Rasmussen, Nigel Spivey éd., Looking at Greek Vases, Cambridge, 1991, p. 12-35.

- BeCTARTE, 2006 : Hélène Bectarte, « ‘Tenir un miroir' dans l'art funéraire antique », dans Lydie Bodiou, Dominique Frère, Véronique Mehl éd., L'expression des corps. Gestes, attitudes, regards dans l'iconographie attique, Rennes, 2006, p. 165-180.

- Bielman, 2002 : Anne Bielman, Femmes en public dans le monde hellénistique, Paris, 2002. 
- BLoK, 1995 : Josine Blok, The Early Amazons. Modern and Ancient Perspectives on a Persistent Myth, Leyde / New York / Cologne, 1995.

- BOEHRINGER, 2007 : Sandra Boehringer, L'homosexualité féminine dans l'Antiquité grecque et romaine, Paris, 2007.

- BONFANTE, 1989 : Larissa Bonfante, « Nudity as a Costume in Classical Art », dans American Journal of Archaeology, 93, 1989, p. 543-570.

- BREMEN, 1983 : Riet Van Bremen, « Women and Wealth », dans Averil Cameron, Amélie Kuhrt éd., Images of Women in Antiquity, Londres, 1983, p. 223-241.

- BREMEN, 1996 : Riet Van Bremen, The Limits of Participation. Women and Civic Life in the Greek East in the Hellenistic and Roman Period, Amsterdam, 1996.

- BRULÉ, 2006 : Pierre Brulé, « Bâtons et bâton du mâle, adulte, citoyen », dans Lydie Bodiou, Dominique Frère, Véronique Mehl éd., L'expression des corps. Gestes, attitudes, regards dans l'iconographie attique, Rennes, 2006, p. 75-83.

- ConNelly, 2007 : Joan Breton Connelly, Portrait of a priestess: women and ritual in ancient Greece, Princeton, 2007.

- DAVIDSON, 1997 : James N. Davidson, Courtesans and fishcakes: the consuming passions of classical Athens, Londres, 1997.

- Demand, 2002 : Nancy Demand, « Gender Studies and History: participation and power », dans Stanley M. Burstein éd., Current Issues and the Study of Ancient History, Claremont,2002, p. 31-43.

- ELıoт, 1968 : Charles Eliot, Mary Eliot, « The Lechaion cemetery near Corinth », dans Hesperia 37/4, 1968, p. 345-350.

- FERRARI, 2002 : Gloria Ferrari, Figures of speech. Men and maidens in Ancient Greece, Chicago / Londres, 2002.

- FERRARI, 2004 : Gloria Ferrari, « The Anodos of the bride », dans Dimitrios Yatromanolakis, Panagiotis Roilos éd., Greek ritual poetics, Washington, 2004, p. 245-260.

- FEYEL, 2006 : Christophe Feyel, Artisans dans les sanctuaires grecs aux époques classique et hellénistique à travers la documentation financière, Athènes / Paris, 2006.

- FougEYrollas et al., 2003 : Dominique Fougeyrollas-Schwebel, Christine Planté, Michèle RiotSarcey, Claude Zaidman éd., Le genre comme catégorie d'analyse. Sociologie, histoire, littérature, Paris, 2003.

- FoxHALl, 1997 : Lin Foxhall, « Pandora Unbound: A Feminist Critique of Foucault's History of Sexuality », dans David Henry, James Larmour, Paul Allen Miller, Charles Platter éd., Rethinking Sexuality: Foucault and Classical Antiquity, Princeton, 1997, p. 122-137.

- FrontISI-Ducroux, 1997 : Françoise Frontisi-Ducroux, « L'œil et le miroir », dans Jean-Pierre Vernant, Françoise Frontisi-Ducroux, Dans l'œil du miroir, Paris, 1997, p. 51-250.

- Frontisi-Ducroux, 1998 : Françoise Frontisi-Ducroux, « Le sexe du regard », dans Paul Veyne, François Lissarrague, Françoise Frontisi-Ducroux, Les mystères du gynécée, Paris, 1998, p. 199-276.

- FrontISI-DUCRouX, LisSARRAGUE, 2001 : Françoise Frontisi-Ducroux, François Lissarrague, « Corps féminin, corps virginal : images grecques », dans Louise Bruit Zaidman, Gabrielle Houbre, 
Christiane Klapisch-Zuber, Pauline Schmitt-Pantel éd., Le corps des jeunes filles de l'Antiquité à nos jours, Paris, 2001, p. 51-61.

- FrontISI-Ducroux, 2004 : Françoise Frontisi-Ducroux, « Images grecques du féminin : tendances actuelles de l'interprétation », dans Femmes et images, Clio HFS 19, 2004, p. 135-147.

- Frontisi-Ducroux, 2007 : Françoise Frontisi-Ducroux, « La fille de Dibutade ou l'inventrice inventée », dans Cahiers du Genre, 43, 2007, p. 129-169.

- FrontISI-Ducroux, LisSARRAGUE, 2004 : Françoise Frontisi-Ducroux, François Lissarrague, « Vingt ans de vases grecs. Tendances actuelles des études en iconographie grecque (1970-1990) », dans Mètis V 1-2, 1990, p. 205-224.

- GEoRGoudi, (1993) 2003 : Stella Georgoudi, « Lysimachè, la prêtresse », dans Nicole Loraux éd., La Grèce au féminin (Rome/Bari, 1993), Paris 2003, p. 167-213.

- GHERCHANOc, 2006 : Florence Gherchanoc, « Le(s) voile(s) de mariage dans le monde grec : se voiler, se dévoiler. La question particulière des anakaluptêria », dans Mètis, N. S., 4, 2006, p. 239-267.

- GHERCHANOC, HUET, 2007 : Florence Gherchanoc, Valérie Huet, « S’habiller et se déshabiller en Grèce et à Rome (I). Pratiques politiques et culturelles du vêtement. Essai historiographique », dans Revue historique, CCCIX/1, 2007, p. 3-30.

- GODELIER, 2005 : Maurice Godelier, « Femmes, sexe ou genre ?», dans Margaret Maruani éd., Femmes, genre et sociétés. L'état des savoirs, Paris, 2005, p. 15-20.

- HofFMAN, 2006 : Geneviève Hoffman, « Ordre et variété dans la gestuelle des monuments funéraires attiques de l'époque classique », dans Lydie Bodiou, Dominique Frère, Véronique Mehl éd., L'expression des corps. Gestes, attitudes, regards dans l'iconographie attique, Rennes, 2006, p. 61-74.

- HALPERIN, (1990) 2000, David M. Halperin, One Hundred Years of Homosexuality, New York / Londres, 1990 ; trad. fr. : Cent ans d'homosexualité et autres essais sur l'amour grec, Paris, 2000.

- HURWIT, 2007 : Jeffrey M. Hurwit, « The problem with Dexileos : heroic and other nudities in greek art », dans American Journal of Archaeology, 111, 1 janvier 2007, p. 35-60.

- IRIARTE, 2007 : Ana Iriarte, « Le genre des habits et le tissage de la nudité en Grèce ancienne », dans Violaine Sebillotte Cuchet, Nathalie Ernoult éd., Problèmes du genre en Grèce ancienne, Paris, 2007, p. 289-301.

- KRON, 1996 : Uta Kron, « Priesthoods, dedications and euergetism. What part did religion play in the political and social status of greek women? », dans Pontus Hellström, Brita Alroth éd., Religion and power in the ancient greek world, (colloque, Uppsala, 1993), Uppsala, 1996, p. 139-182.

- LANG, 1974 : Mabel Lang, The Athenian Agora: graffiti and dipiniti, Princeton, 1974.

- LEWIS, 2002 : Sian Lewis, The Athenian woman. An iconographic handbook, Londres / New York, 2002 .

- LisSARRAGUE, 1987 : François Lissarrague, « De la sexualité des satyres », dans Mètis, 2, 1987, p. 63-90.

- LISSARRAGUE, 1990 : François Lissarrague, L'autre guerrier. Archers, peltastes, cavaliers dans l'imagerie attique, Paris / Rome, 1990. 
- LISSARRAGUE, 1991 : François Lissarrague, « Femmes au figuré », dans Pauline Schmitt-Pantel éd., Histoire des femmes en Occident, 1. L'Antiquité, Paris, 1991, p. 159-251.

- LISSARRAGUE, 1995 : François Lissarrague, « Women, Boxes, Containers: some Signs and Metaphors », dans Ellen Reeder éd., Pandora. Women in classical Greece, Princeton, 1995, p. 91-101.

- LisSARRAGUE, 1998 : « Images du gynécée », dans Paul Veyne, François Lissarrague, Françoise Frontisi-Ducroux, Les mystères du gynécée, Paris, 1998, p. 155-198.

- LisSARRAGUe, 2006 : François Lissarrague, « Comment peindre des Érinyes ? », dans Mètis, N. S., 4, 2006, p. 51-70.

- LORAUX, 1981a : Nicole Loraux, L'invention d'Athènes. Histoire de l'oraison funèbre dans la cité classique, Paris, 1981.

- LoRAuX, 1981b : Nicole Loraux, Les enfants d'Athéna. Idées athéniennes sur la citoyenneté et la division des sexes, Paris, 1981.

- LoRAUX, 1985 : Nicole Loraux, Façons tragiques de tuer une femme, Paris, 1985.

- LoRAUX, 1989 : Nicole Loraux, Les expériences de Tirésias, Paris, 1989.

- LORAUX, 1990 : Nicole Loraux, Les mères en deuil, Paris, 1990.

- LoRAUX, 1999 : Nicole Loraux, La voix endeuillée. Essai sur la tragédie grecque, Paris, 1999.

- LougovayA-Ast, 2006 : Julia Lougovaya-Ast, « Myrrhine, the First Priestess of Athena Nike », dans Phoenix, 60, 2006, p. 211-225.

- MiLNE, 1945 : Marjorie J. Milne, « A prize for wool-working », dans American Journal of Archaeology, 49, 1945, p. 528-33.

- PotTs, 1994 : Alex Potts, Flesh and the Ideal. Winckelmann and the origins of art history, New Haven / Londres, 1994.

- REEDER, 1995 : Ellen D. Reeder éd., Pandora. Women in classical Greece, Baltimore / Princeton, 1995.

- ROTROFF, LAMBERTON, 2006 : Susan I. Rotroff, Robert D. Lamberton, Women in the Athenian Agora, Princeton, 2006.

- Schmitt-PANTEL, 2003 : Pauline Schmitt-Pantel, « Le banquet et le 'genre'sur les images grecques, propos sur les compagnes et les compagnons », dans Pallas 61, 2003, p. 83-95.

- SeBillotte Cuchet, 2007 : Violaine Sebillotte Cuchet, « Les antiquistes et le genre ", dans Violaine Sebillotte Cuchet, Nathalie Ernoult éd., Problèmes du genre en Grèce ancienne, Paris, 2007, p. 11-26.

- Sebillotte Cuchet, ERnoult, 2007 : Violaine Sebillotte Cuchet, Nathalie Ernoult éd., Problèmes du genre en Grèce ancienne, Paris, 2007.

- SHAPIRO, 1992 : Alan Shapiro, « Eros in love : Paederasty and Pornography in Greece », dans Amy Richlin éd., Pornography and Representation in Greece and Rome, Oxford, 1992, p. 91-111.

- SouRvinOU-INWOOD, 1995 : Christiane Sourvinou-Inwood, « Male and female, public and private, ancient and modern », dans Ellen D. Reeder éd., Pandora. Women in classical Greece, Baltimore / Princeton, 1995, p. 111-120. 
- SOURVINOU-INWOOD, 2004 : Christiane Sourvinou-Inwood, « Gendering the athenian funeral: Ritual reality and tragic manipulation », dans Dimitrios Yatromanolakis, Panagiotis Roilos éd., Greek ritual poetics, Washington, 2004, p. 161-188.

- VillanueVA-Puig, 2000 : Marie-Christine Villanueva-Puig, Mainades. Recherches sur la genèse du thiase féminin de Dionysos, des origines à la fin de la période archaïque. Essai d'iconographie religieuse, thèse d'état-université de Paris I, 2000.

- VillanueVA-Puig, 2004 : Marie-Christine Villanueva-Puig, « Des coupes à yeux de la céramique grecque ", dans Journal des savants, janvier-juin 2004, p. 3-20.

- WALDNER, 2000 : Katharina Waldner, Geburt und Hochzeit des Kriegers, Berlin, 2000.

- WEBSTER, 1972 : Thomas Bertram Lonsdale Webster, Potter and Patron in Classical Athens, Londres, 1972.

- WINKLER, (1990) 2005 : John J. Winkler, The constraints of desire: the anthropology of sex and gender in ancient Greece, New York / Londres, 1990 ; trad. fr. : Désir et contraintes en Grèce ancienne, Paris, 2005.

\section{NOTES DE FIN}

1. Ainsi la fameuse stèle d'Amphareté avec trois générations représentées en deux catégories d'âge : Inscriptiones Graecae II $^{2}$ 10650, Athènes, Musée du Céramique et LEWIS, 2002, p. 55.

2. Un récent article analyse la stèle de Dexiléos (stèle de Dexiléos, Athènes, Musée du Céramique) d'un point de vue assez proche : le vainqueur est vêtu et domine un vaincu représenté nu, selon le code de la nudité héroïque. Dans cet exemple, la distinction nu/vêtu ne discrimine pas les sexes mais des types d'armes, celles du cavalier et celles de l'hoplite (HURWIT, 2007).

3. F. Frontisi-Ducroux a souligné dans une étude entièrement consacrée à ce sujet la hiérarchie qui prévaut dans les échanges de regards, ou leur absence, entre l'homme et la femme (FronTISIDucroux, 1998).

\section{RÉSUMÉS}

Cet article dresse un panorama des gender studies dans le domaine de l'iconographie grecque des époques archaïque et classique. Il montre comment les spécialistes développent préférentiellement deux approches dont les méthodes sont diamétralement opposées. L'approche documentaire, en soulignant les activités féminines représentées sur les images et en associant ces activités aux sources épigraphiques ou archéologiques, tend à renouveler considérablement le discours des historiens sur la subordination et l'anonymat des femmes. L'approche symbolique, en décrivant les signes du masculin et les signes du féminin, révèle la façon dont les constructions de genres se réalisent à l'intérieur de ce système de communication très codifié qu'est la peinture sur vases. Ces grandes directions de recherche, qui sont ici abordées dans un esprit de complémentarité, introduisent de nouveaux questionnements, voire de nouvelles hypothèses sur des dossiers bien connus, celui du nu héroïque et celui de l'homosexualité tant masculine que féminine.

This article presents an overview of gender studies within the context of Greek iconography from the archaic and classic periods. It shows how specialists tend to develop two different approaches, whose methods are diametrically opposed. The documentary approach, which emphasizes the presence of representations of feminine activities in images and associates them 
with epigraphic or archaeological sources, tends to rekindle the discourse of historians on the subordination and anonymity of women. The symbolic approach, which describes the signs associated with the masculine and the feminine, reveals the way in which gender is constructed within the highly codified system of communication that caracterizes vase-painting. These two principal directions in research, presented here as complementary, bring new questions and even new hypotheses to well-known topics, namely the heroic nude and the theme of homosexuality, both masculine and feminine.

Dieser Artikel gibt einen Überblick über die Gender Studies im Bereich der Ikonographie der griechischen Archaik und Klassik. Er zeigt auf, wie die Spezialisten vorrangig zwei Ansätze verfolgen, deren Methoden genau entgegengesetzt sind. Der dokumentarische Ansatz versucht, den historischen Diskurs über die Unterordnung und die Anonymität der Frauen entscheidend zu erneuern, indem er auf Darstellungen weiblicher Aktivitäten eingeht und diese mit epikgraphischen und archäologischen Quellen verknüpft. Der symbolische Ansatz deckt durch die Beschreibung von männlichen und weiblichen Zeichen die Art der Geschlechterkonstruktionen auf, die sich innerhalb des stark kodifizierten Kommunikationssystems der Gefäßmalerei ergeben. Diese Leitlinien in der Forschung, die hier in ihrer Gegensätzlichkeit dargestellt werden, führen zu neuen Fragestellungen und sogar zu neuen Hypothesen in bezug auf altbekannte Themen, wie zum Beispiel der heroische Akt und die sowohl männliche, als auch weibliche Homosexualität.

Questo articolo presenta un panorama degli studi di genere (gender studies) nel campo dell'iconografia greca dell'epoca arcaica e classica e intende mostrare come gli specialisti tendano principalmente all'elaborazione di due approcci metodologici diametralmente opposti. L'approccio documentario, nel sottolineare le attività femminili rappresentate nelle immagini e nell'associarle alle fonti epigrafiche o archeologiche, tende a rinnovare in modo considerevole le interpretazioni storiche della subordinazione e dell'anonimato delle donne. L'approccio simbolico, nel descrivere i segni del maschile e del femminile, mette in evidenza la maniera in cui si realizzi la costruzione dei generi all'interno di un sistema codificato come quello della pittura vascolare. Questi due grandi orientamenti della ricerca, che sono qui trattati in maniera complementare, introducono nuovi interrogativi, o meglio nuove ipotesi su ambiti ben conosciuti come il nudo eroico e l'omosessualità maschile e femminile.

Este artículo elabora un panorama de los gender studies en el ámbito de la iconografía griega de la época arcaica y de la clásica. Muestra cómo los especialistas desarrollan preferencialmente dos enfoques cuyos métodos se oponen diametralmente. El enfoque documental, al destacar las actividades femeninas representadas sobre las imágenes y al asociar estas actividades a las fuentes epigráficas o arqueológicas, tiende a renovar considerablemente el discurso de los historiadores sobre la subordinación y el anonimato de las mujeres. El enfoque simbólico, al describir las señas del masculino y las del femenino, revela la forma en que las construcciones de género se realizan dentro de este sistema de comunicación muy codificado que es la pintura sobre jarrones. Estos grandes rasgos de investigación, que se abordan aquí en un espíritu de complementariedad, introducen nuevos cuestionamientos, o incluso nuevas hipótesis sobre expedientes bien conocidos, el del desnudo heroico y el de la homosexualidad tanto masculina como femenina. 


\section{INDEX}

Index géographique : Grèce

Keywords : Ancient art history, gender studies, gender, sexual identity, masculinity, femininity, representations, iconography, social history, gender history, literature

Mots-clés : histoire de l'art antique, gender studies, genre, identité sexuelle, masculinité, féminité, représentations, iconographie, histoire sociale, histoire du genre, littérature Index chronologique : ANTIQUITÉ

\section{AUTEUR}

\section{VIOLAINE SEBILLOTTE CUCHET}

Ancienne élève de l'École normale supérieure de Fontenay-Saint-Cloud, Violaine Sebillotte Cuchet est maîtresse de conférences d'histoire grecque à l'université Paris I Panthéon-Sorbonne et membre de l'équipe Phéacie, Pratiques culturelles des sociétés grecque et romaine. Ses recherches portent à la fois sur l'histoire des émotions dans leur rapport avec l'anthropologie politique (Libérez la patrie! Patriotisme et politique en Grèce ancienne, Paris, 2006) et sur les rapports féminin-masculin, de genre, dans la Méditerranée grecque archaïque et classique. 